\title{
PERINEAL ECTOPIC TESTIS - A RARE ANOMALY WITH EMPTY SCROTUM
}

\author{
Safdar Hussain Awan, Naveed Ahmed, C. Aqeel Safdar, Iftikhar Ahmed, Hashim Zaidi* \\ Pak Emirates Military Hospital/National University of Medical Sciences (NUMS) Rawalpindi Pakistan, *Combined Military Hospital \\ Multan/National University of Medical Sciences (NUM) Pakistan
}

\begin{abstract}
Undescended testis is a very common presentation in male paediatric population but testis at ectopic sites is a very rare pathology. One of the ectopic sites is perineum and it accounts for only $1 \%$ of all cases of undescended testis. We report a case of an 11 yr old boy who presented with an empty left hemiscrotum and detailed examination revealed a soft tissue mass on the corresponding side in the perineum. Surgical exploration was carried out during which it was revealed that mass was actually testis at ectopic site with adequate length of the spermatic cord. Testis was mobilized and fixed in the ipsilateral hemiscrotum.
\end{abstract}

Keywords: Ectopic testis, Perineum, Spermatic cord. This is an Open Access article distributed under the terms of the Creative Commons Attribution License (http://creativecommons.org/licenses/by/4.0), which
permits unrestricted use, distribution, and reproduction in any medium, provided the original work is properly cited.

\section{INTRODUCTION}

Testicular maldescent is the most common anomaly of the genitalia seen in $0.2-1 \%$ of all men. Most of these testes get arrested along its normal pathway, resulting in abdominal, inguinal or high scrotal testis. About $5 \%$ of undesceded testis are ectopic. The most common ectopic sites in descending order are superficial inguinal pouch, perineum, root of penis, femoral triangle/ upper thigh and contralateral scrotum ${ }^{1}$. Perineal ectopic testis is a rare encounter in paediatric surgery accounting for about $1 \%$ of all cases of undescended testis ${ }^{2}$.

The first case was reported by Sir John Hunter in 1786. Approximately, 175 cases of perineal ectopic testes have been reported in the literature and $80 \%$ of these cases are unilateral. Perineal ectopic testis is a condition in which the testis has descended, but occupied an abnormal position between the penoscrotal raphe and the genitofemoral fold. Perineal ectopic testes are prone to trauma, torsion, infertility in bilateral cases and malignancy ${ }^{3}$.

\section{CASE REPORT}

An 11 year old boy presented to out patient department with complaint of empty left hemi-

Correspondence: Dr Naveed Ahmed, Dept of Pediatric Surgery, Combined Military Hospital Quetta Pakistan

Received: 11 Jun 2018; revised received: 24 Mar 2019; accepted: 21 Jun 2019 scrotum. Examination revealed a healthy adolescent with under developed and empty left hemiscrotum with no evidence of inguinal hernia. The right testis was normally located. No mass was palpable in inguinal canal however a firm,

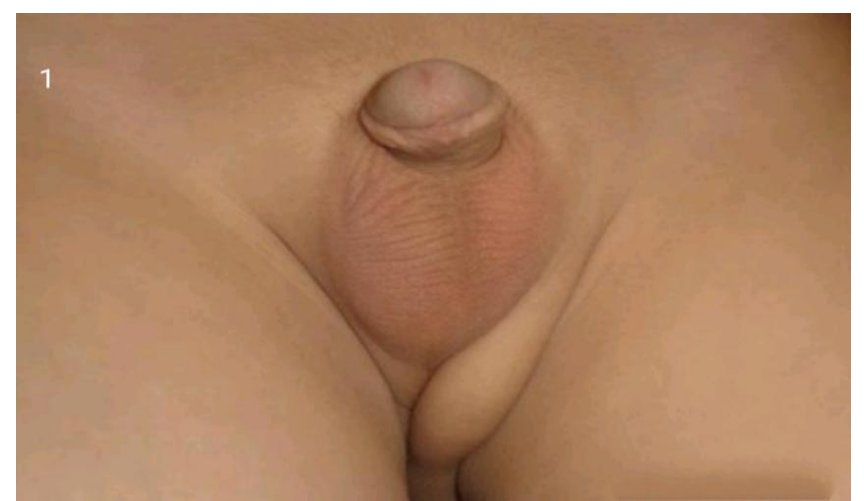

Figure-1: Underdeveloped left hemiscrotum and left perineal swelling due to ectopic testis.

mobile and non tender left perineal mass was palpable that measured around $3 \times 2 \times 2 \mathrm{~cm}$ (fig1 ). A clinical diagnosis of left perineal ectopic testis was made that was confirmed on ultrasound. Parents were counselled and surgical exploration and orchidopexy was planned. Exploration through inguinal incision revealed gubernaculum attached with perineal tissues with adequate length of the cord. Testis was mobilized (fig-2) and orchidopexy was done by fixing the testis in the ipsilateral scrotum using the standard dartos pouch technique (fig-3). 


\section{DISCUSSION}

Testicular development and descent from abdomen to scrotum is a complex and multistage process which starts from 7 th to 35th week of gestation. Gubernaculum, which is thickened peritoneal tissue, actually guides the testis through a

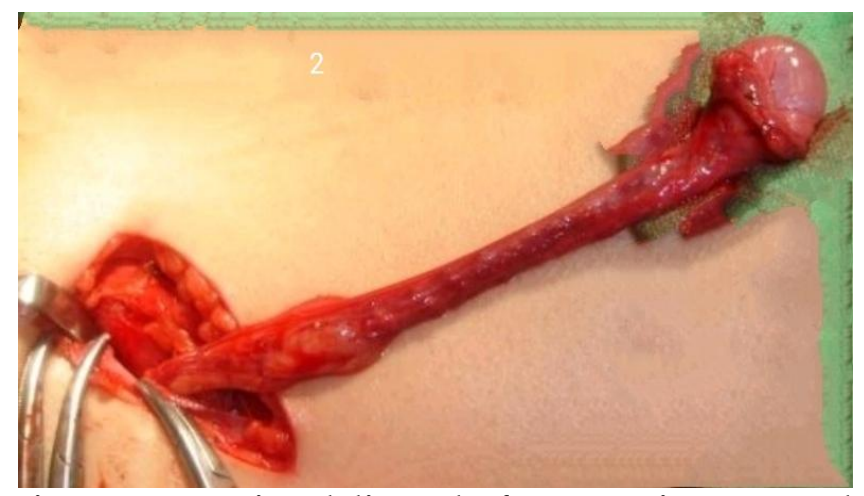

Figure-2: Testis delivered from perineum and spermatic cord mobilized.

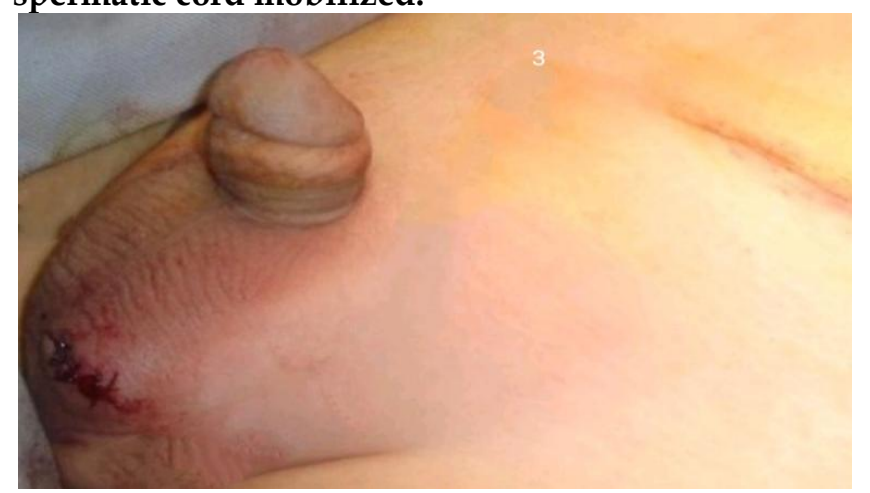

Figure-3: Groin and scrotal wounds after left orchidopexy in dartos pouch.

(Note: Photographs shown after seeking permission from the parents of the child)

programmed pathway through its abdominal and inguinal route. This process can get arrested any where at its normal course causing cryptorchidism, the commonest genital malformation in boys with one-third of premature boys and 2-5\% of full-term boys being affected ${ }^{4}$. The risk factors contributing to this arrest can be prematurity and low birth weight also ${ }^{5}$. Any abnormality in this programmed descent can lead the testis to a location that does not lie in its normal course i.e. perineum, root of penis, upper rhigh or even abdominal wall. In this regard, abnormal position of genitofemoral nerve is also believed to play a role in abnormal migration of the gubernaculum and pushes the testis to abnormal position' ${ }^{6}$. Perineal ectopic testis is a rare congenital condition with a prevelance of $1 \%$ of all cases of undescended testes7. Prompt recognition of this anomaly is very important because due to rarity of this condition one can miss the common associated problems with this condition like hypospadias, scrotal anomalies, contralateral undesended testis and inguinal hernia ${ }^{8}$.

So, the presentation of this condition can be diverse and clinician should have high index of suspicion in patients with empty scrotum with associated inguinal hernia or hypospadias. Although, in one study, there was no histologic difference between undescended and ectopic testis but long term followup suggests increased incidence of subfertility and malignancy in ectopic testis 9 . Moreover, due to advancements in diagnostic modalities, now it is possible to diagnose the ectopic perineal testis antenatally ${ }^{10}$. Treatment of ectopic testis is always surgical with special emphasis on detailed parental counselling and long term followup.

\section{CONCLUSION}

Detailed clinical examination of any boy with empty scrotum at the time of birth and at the time of presentation in clinic should include the ectopic sites also especially if associated with inguinal hernia or hypospadias.

\section{CONFLICT OF INTEREST}

This study has no conflict of interest to be declared by any author.

\section{REFERENCES}

1. Ramareddy RS, Alladi A, Siddappa OS. Ectopic testis in children: experience with seven cases. J Pediatr Surg 2013; 48(3): 538-41.

2. Celayir AC, Sander S, Elicevik M. Timing of surgery in perineal ectopic testes: analysis of 16 cases. Pediatr Surg Int 2013; 17: 167-68

3. Jlidi S, Eschaiels A, Ghorbel S, Khemakhem R, Khalifa SB, Chaouachi B, et al. Perineal ectopic testis: report of 4 paediatric cases. Prog Uro 2014; 4: 532-33.

4. Toppari J, Kaleva M. Maldescensus testis. Horm Res 1999; 51(6): 261-19.

5. Vieira JFL, Brahme G, Pandya N, Desai A. Empty scrotum: undescended testis or ectopic? BMJ Case Rep 2013; 2013: bcr2013009152 
6. Hutson JM. Undescended testis, torsion, and varicocele. In: Gross feld JL, O'Neil JAJ, Fonkalsrud EW, Coran AG, eds. Pediatric surgery. $6^{\text {th }}$ ed. Philadelphia: Mosby; 2006: 1193-214.

7. Tasdemir C, Tuygun UO. Perineal ectopic testis: a case report. Eur Rev Med Pharmacol Sci 2011; 15(11): 1318-19.

8. Nouira F, Ben Y, Jlidi S, Sarrai N, Chariag A, Ghorbel S, Khemakhem R, Chaouachi B. Management of perineal ectopic testes.
Tunis Med 2011; 89(1): 47-49.

9. Hutcheson JC, Snyder HM, Zuñiga ZV, Zderic SA, Schultz DJ, Canning DA, et al. Ectopic and undescended testes: 2 variants of a single congenital anomaly? J Urol 2000; 163(1): 961-63.

10. Mazneikova V, Markov D. Antenatal ultrasound diagnosis of perineal ectopic testis - a case report. J Euro 2001; 13(1): 31-33. 